\title{
A CONSTRUÇÃO DE NOVOS CENTROS DE ATENDIMENTO PARA A EDUCAÇÃO INFANTIL E A QUEDA DA TAXA DE NATALIDADE: UM DIAGNÓSTICO DE CURITIBA
}

\author{
THE BUILDING OF NEW CHILDHOOD EDUCATION CENTERS AND \\ FALLING BIRTH RATES: AN EVALUATION OF CURITIBA
}

\author{
Adriano Benedito Laurindo ${ }^{1}$ \\ Marília de Souza ${ }^{2}$
}

\section{RESUMO}

Este artigo mostra um diagnóstico dos investimentos na construção de espaços de atendimento na educação infantil em Curitiba, que em breve atingirá a demanda das vagas necessárias para garantir a meta nacional de atender $50 \%$ das crianças até 2020. Em contrapartida, dados da área da saúde revelam que o número de crianças nascidas diminui anualmente, e poderá chegar o momento em que não será mais necessário ampliar os investimentos em construção de novos equipamentos e contratação de pessoal para a educação infantil. Porém, observando a constante queda na taxa de natalidade, percebe-se que há necessidade de planejamento, evitando que toda a estrutura se torne um problema, com desperdício de verbas públicas aplicadas de forma eleitoreira ou assistencialista. Desta forma, com planejamento eficiente, buscando adequar os investimentos com base no presente e atento a novas ideias e desafios, o poder público poderá destinar recursos para garantir um atendimento de qualidade.

Palavras-chave: Educação Infantil; Investimento; Qualidade.

\begin{abstract}
This article presents and evaluation of investments in building education centers for children in Curitiba, which will soon achieve the levels of demand for the necessary places to ensure the national goal of meeting the needs of $50 \%$ of children by 2020 . On the other hand, data from the field of healthcare reveal that the number of children born falls every year, and the time could come when it will no longer be necessary to increase investments in the building of new equipment and hiring staff to educate children. However, noting the constant fall in birth rates, one sees that there is a need for planning to avoid the whole structure becoming a burden, with public funds wasted for electoral or welfare purposes. Thus, with efficient planning in an attempt to adapt investments to the present and open to new ideas and challenges, the authorities can earmark resources in order to ensure quality services.
\end{abstract}

Key words: Childhood Education; Investment; Quality.

\footnotetext{
${ }^{1}$ Mestrando do Programa de Pós-Graduação em Planejamento e Governança Pública, Universidade Tecnológica Federal do Paraná (UTFPR). E-mail: adrianolaurin@gmail.com

${ }^{2}$ Doutora em Sciences Mécaniques pour IIngénieur pela Université de Technologie de Compiègne. Atua no SESI/SENAI/IEL Paraná). E-mail: mariliasouza@fiepr.org.br
} 


\section{Introdução}

Os investimentos realizados pelo poder público para atender à demanda de vagas da educação infantil sempre foram questionados pela sociedade em geral. Levando em consideração que as famílias buscam um lugar onde deixar os filhos em segurança, e assim poderem trabalhar, o atendimento à população que necessita desse serviço ainda é insuficiente.

Devido ao clamor assistencialista, a falta de vagas nas creches é um assunto constantemente incluído na pauta de discussão dos processos eleitorais.

As instituições que prestam esse tipo de atendimento são denominadas Centros, Escolas e Unidades de Educação Infantil. No estado do Paraná, de acordo com a Deliberação n $02 / 2005$ do Conselho Estadual de Educação do Paraná (CEE-PR), parágrafo $1^{\circ}$, "as diferentes denominações hoje existentes (creches e/ou pré-escolas), para o atendimento às crianças de zero a seis anos, serão adequadas gradativamente em sua estrutura, transformando-se em Centros de Educação Infantil" (PARANÁ, 2005). Conhecidas pela sociedade como creches, essas instituições surgiram muito tempo depois da implantação das escolas tal qual as conhecemos, devido à transformação histórica da sociedade, quando as "mães de família" tiveram que deixar os filhos para sair em busca de oportunidades de emprego. Para atender a essa necessidade da população, o setor púbico se organizou para criar espaços onde as crianças pudessem ser deixadas e cuidadas durante o período em que as mães estivessem trabalhando, sem priorizar a educação.

Tratar essas crianças como parte de um processo educacional voltado à formação de cidadãos preparados para a sociedade onde vivem é algo recente na história do Brasil.

Atualmente, grande parte dos recursos investidos na educação é destinada à construção de novos espaços para atendimento, porém a administração pública deverá estar atenta ao número de unidades necessárias para garantir esse atendimento, pois é visível a diminuição da composição familiar, com um número reduzido de crianças nas famílias e até mesmo de casais que optam por não ter filhos. Portanto, promessas eleitoreiras que anunciam "zerar as filas de espera nas creches públicas" poderão se tornar um problema se a taxa de natalidade continuar em declínio. Conhecer o número ideal de unidades de atendimento proporcionará que todo recurso atualmente investido na ampliação da estrutura física seja destinado à qualidade dos serviços públicos prestados.

\section{Justificativa}

Os servidores da área de educação enfrentam diretamente a pressão de órgãos e instituições do poder público, como Conselho Tutelar, Ministério Público Federal e demais membros da sociedade em geral, para atender à grande demanda de oferta de vagas em creches públicas. Durante vários anos, os profissionais do magistério têm acompanhado todo o investimento da prefeitura municipal de Curitiba na construção de novas unidades de atendimento para a educação infantil e contratação de novos servidores em ritmo acelerado para atender a essa necessidade. Em contrapartida, segundo dados disponibilizados pela Secretaria Municipal de Saúde, observa-se uma queda na taxa de natalidade da população. A longo prazo, sem o devido planejamento, a cidade terá estrutura física preparada para atender a uma demanda diferente da situação atual. 
Portanto, cabe à população e à sociedade acompanhar essa situação, pois, quando não houver a necessidade de mais investimentos na estrutura física, o foco do investimento poderá voltar-se à uma área que historicamente caminha a passos lentos no país, considerada o pontochave para formar uma sociedade melhor: a qualidade da educação.

\section{3. $O$ contexto histórico da educação infantil}

Durante um bom período na história da humanidade, a responsabilidade pela educação da criança era obrigação exclusiva das famílias ou do grupo social no qual estavam inseridas. A criança tornava-se membro desse grupo, convivendo, portanto, com os adultos e outras crianças, e adquiria os conhecimentos necessários para seu desenvolvimento na sociedade, seguindo os costumes e padrões culturais. Não havia nenhuma instituição responsável por compartilhar com as famílias o desenvolvimento da criança.

As instituições de educação infantil e pré-escolas surgiram após a implantação das escolas, associadas à necessidade de a mãe, durante a Revolução Industrial, ter onde deixar os filhos e poder sair em busca de uma oportunidade de emprego. Ao mesmo tempo, o nascimento do pensamento pedagógico moderno, organizado pelo desenvolvimento da Europa após o século XVII, e até mesmo a influência da igreja tiveram papéis importantes no processo de alfabetização da sociedade, passando pelas transformações necessárias para a implantação da sociedade industrial, que exigia uma educação voltada às novas ocupações do mercado do trabalho.

A Educação Infantil, e em particular as creches, destinava-se ao atendimento de crianças pobres e organizava-se com base na lógica da pobreza, isto é, os serviços prestados - seja pelo poder público seja por entidades religiosas e filantrópicas - não eram considerados um direito das crianças e de suas famílias, mas sim uma doação, que se fazia - e muitas vezes ainda se faz - sem grandes investimentos. Sendo destinada à população pobre, justificava-se um serviço pobre. Além dessas iniciativas, também as populações das periferias e das favelas procuraram criar espaços coletivos para acolher suas crianças, organizando creches e pré-escolas comunitárias. Para tal, construíram e adaptaram prédios com seus próprios e parcos recursos, o que seguem fazendo na ausência do Estado. (BRASIL, 2006, p. 7).

No Brasil, ainda é possível observar que crianças socialmente menos favorecidas, e que mais poderiam se beneficiar dos programas de educação, ainda continuam sem acesso.

A oferta apresenta qualidade aquém das referências reconhecidas como adequadas [...] e geralmente é pior nos estabelecimentos nos quais se encontram as crianças desses segmentos sociais desfavorecidos. Na União Europeia, onde está a maioria dos países da OCDE, os programas de educação e cuidados com as crianças de até cinco/seis anos de idade foram estabelecidos também como política de igualdade entre homens e mulheres, uma vez que podem liberá-las 
para atuar no mercado de trabalho. O Brasil, ainda que apresente taxa de participação feminina na força de trabalho (58\%) semelhante à maioria dos países da OCDE, e até supere a de vários deles, bem como a de países vizinhos sul-americanos, não mostra extensão de atendimento às crianças condizente com essa ocupação feminina. Assim, grande parte das famílias não conta com creches para seus filhos, sendo obrigadas a deixá-los aos cuidados de vizinhos ou parentes, muitas vezes em condições bastante precárias. (UNESCO, 2010, p. 5).

Desta forma, o surgimento das instituições de educação infantil foram consequência das mudanças econômicas, políticas e sociais que ocorreram na sociedade a partir da incorporação das mulheres ao mercado de trabalho.

\section{Avanços na educação infantil}

Há uma diversidade de pesquisas sobre os avanços da educação infantil no cenário nacional, mas são poucos os dados oficiais. Em 2010, a UNESCO fez uma comparação das Metas de Expansão do Atendimento Educacional previstas no PNE (BRASIL, 2001), utilizando dados oficiais do ano de 2008 (ver Tabela 1).

TABELA 1 - PNE: Metas de expansão do atendimento educacional

\begin{tabular}{l|c|c|c|c}
\hline $\begin{array}{l}\text { Níveis } \\
\text { modalidades }\end{array}$ & Faixa etária & $\begin{array}{l}\text { Valores em } \\
\mathbf{2 0 0 1}\end{array}$ & $\begin{array}{l}\text { Valores em } \\
\mathbf{2 0 0 8}\end{array}$ & $\begin{array}{l}\text { Meta PNE para } \\
\mathbf{2 0 1 1}\end{array}$ \\
\hline \multirow{2}{*}{ Educação Infantil } & 0 a 3 & $10,50 \%$ & $18,10 \%$ & $50 \%$ \\
\cline { 2 - 5 } & 4 a 6 & $65,50 \%$ & $79,70 \%$ & $80 \%$ \\
\hline
\end{tabular}

Fontes: BRASIL, 2001; IBGE, 2008; Censo Escolar do Inep (MEC).

A avaliação da UNESCO comparou a meta estabelecida no PNE em 2001 para os dez anos seguintes e, embora a meta para crianças de 4 a 6 anos tenha sido praticamente atingida em 2008, aponta que houve um tímido avanço na educação infantil no atendimento de crianças de 0 a 3 anos no cenário nacional $(18,1 \%)$. A meta nacional não foi atingida em 2011, sendo novamente estabelecida a meta de $50 \%$ até 2020 .

A importância da educação infantil é objeto de estudo em todos os países e apontada no Relatório de Monitoramento Global de EPT:

A educação e os cuidados que a criança recebe em seus primeiros anos afetam seu desenvolvimento por toda a vida. Programas de educação e cuidados na primeira infância podem proporcionar às crianças uma chance melhor de sair da pobreza e superar desvantagens. (UNESCO, 2010, p. 9). 
A maior parte dos investimentos na área da educação pública no Brasil, de forma geral, ainda está voltada à quantidade, buscando atender à demanda de vagas. A falta de investimentos na qualidade da educação pode ser comprovada ao serem observadas as escolas operando com número de alunos além de sua capacidade, falta de vagas para atendimento à educação infantil, escassez de profissionais, professores com carga de responsabilidade muito grande, problemas disciplinares, entre outros.

No Brasil, grande número de ambientes destinados à educação de crianças com menos de 6 anos funciona em condições precárias. Serviços básicos como água, esgoto sanitário e energia elétrica não estão disponíveis para muitas creches e pré-escolas. Além da precariedade ou mesmo da ausência de serviços básicos, outros elementos referentes à infraestrutura atingem tanto a saúde física quanto o desenvolvimento integral das crianças. Entre eles está a inexistência de áreas externas ou espaços alternativos que propiciem às crianças a possibilidade de estar ao ar livre, em atividade de movimentação ampla, tendo seu espaço de convivência, de brincadeira e de exploração do ambiente enriquecido. (BRASIL, 2006, p. 10).

Com todos esses problemas, a instituição tornou-se inconscientemente comprometida com os interesses do capitalismo, cuja principal preocupação era ter apenas um lugar onde as crianças ficassem para que as mães pudessem entrar no mercado de trabalho. Esse modelo atual de organização da escola engessa seu verdadeiro papel: ser o agente transformador da sociedade.

O desenvolvimento da humanidade motiva novas pesquisas capazes de mudar conceitos e derrubar barreiras. Nesta caminhada, é dever de todos cobrar do poder público o investimento da qualidade na educação, para que seja construída uma instituição ética, socializada e com formação crítica baseada em conteúdos, questionadora não só pelo simples fato de questionar, mas com embasamento científico. Esse tipo de aprendizado requer conhecimento, cooperação e intercâmbio de toda a sociedade.

Com o desenvolvimento da economia no Brasil e o aumento das oportunidades de trabalho, as famílias necessitam cada vez mais de um lugar onde deixar os filhos, e "o dever do Estado com a educação será efetivado mediante a garantia de: IV - educação infantil, em creche e pré-escola, às crianças até 5 (cinco) anos de idade" (BRASIL, 1988, artigo 208).

Mesmo com o direito garantido por lei, ainda são muitas as famílias que não conseguem vaga para os filhos em instituições públicas de ensino que ofertem educação infantil, e ainda há muito a se fazer para que seja garantido o atendimento às crianças das famílias que realmente necessitam desse tipo de atendimento.

A Constituição de 1988 representou um grande avanço, ao estabelecer como dever do Estado, por meio dos municípios, garantia à Educação Infantil, com acesso para todas as crianças de 0 a 6 anos a creches e pré-escolas. Essa conquista da sociedade significou uma mudança de concepção. A Educação Infantil deixava de se constituir em caridade 
para se transformar, ainda que apenas legalmente, em obrigação do Estado e direito da criança. (BRASIL, 2006, p. 9).

No ano de 2010, a Conferência Nacional de Educação (Conae) aprovou a ampliação de $1 \%$ do PIB do país destinado anualmente à educação, de forma a atingir $7 \%$ do PIB em 2011 e 10\% em 2014. Dados atuais, e não oficiais, apontam que atualmente os níveis de investimento na educação ainda não ultrapassam 5\% do PIB nacional. A proposta faz parte do novo Plano Nacional de Educação (PNE), que terá vigência de 2011 a 2020. O documento estabelece 20 metas a serem alcançadas pelo país até 2020 e garantirá um aumento significativo nos recursos destinados ao investimento da educação.

Esse investimento aumenta ainda mais a responsabilidade da sociedade brasileira em acompanhar as ações de seus representantes no poder público, que decidirão a forma como esses recursos serão investidos.

Vivemos um momento de reestruturação da educação, com discussões e adequações definidas numa legislação recente, em especial a Lei de Diretrizes e Bases da Educação Nacional (LDB), Lei 9.394/1996.

A LDB regulamenta a educação infantil como primeira etapa da educação básica e "tem por finalidade o desenvolvimento intelectual da criança até seis anos de idade, em seus aspectos físico, psicológico, intelectual e social, complementando a ação da família e da comunidade" (BRASIL, 1996).

Desta forma, a LDB define a educação infantil como um complemento na educação das crianças e derruba a concepção de que as unidades devem substituir as famílias, como muitas vezes é entendido.

A prefeitura municipal de Curitiba passou oficialmente a tratar a educação infantil como um processo de educação a partir de 2003, com a aprovação do projeto que extinguiu a Secretaria Municipal da Criança (SMCR), órgão que administrava as creches da cidade e tinha caráter assistencialista. Com a extinção da SMCR, as creches passaram a ser administradas pela Secretaria Municipal da Educação (SME), e receberam a denominação de Centros Municipais de Educação Infantil (CMEIs), seguindo as determinações previstas na legislação.

Conforme o Plano Nacional de Educação (PNE), cabe aos municípios criar um sistema de acompanhamento, controle e supervisão da Educação Infantil nos estabelecimentos públicos e privados, visando ao apoio técnico-pedagógico para a melhoria da qualidade e à garantia do cumprimento dos padrões mínimos estabelecidos pelas diretrizes nacionais e estaduais (BRASIL, 2001, p. 62-63).

Com o crescimento do atendimento na educação infantil, houve a necessidade de o poder público investir em novos espaços destinados a absorver a demanda de vagas.

Visando definir e implementar a política municipal para atendimento à educação infantil em Curitiba, a Secretaria Municipal de Educação de Curitiba estabeleceu, em 2009, os Parâmetros e Indicadores de Qualidade para as Escolas Municipais que ofertam a educação infantil, um documento que serve de referência para todas as unidades de educação infantil na cidade. 
Os Parâmetros Municipais de Qualidade para as Escolas que ofertam a educação infantil foram elaborados com base nos parâmetros do MEC (BRASIL, 2006), nas observações e relatos dos profissionais da educação infantil e nas experiências significativas vivenciadas pelas unidades nos últimos anos, considerando a organização dos espaços, a diversidade e qualidade de propostas oferecidas às crianças, o investimento na gestão democrática e, principalmente, o interesse e o desenvolvimento dos profissionais para o planejamento $\mathrm{e}$ desenvolvimento do trabalho com as crianças. Isso demonstra que é possível Curitiba avançar ainda mais no sentido de oferecer às crianças iguais oportunidades de acesso à educação infantil de qualidade. (CURITIBA, 2009, p. 9).

Questões como aprendizagem, desenvolvimento, ampliação de conhecimentos, proteção, segurança, alimentação adequada, que garanta o desenvolvimento físico e a saúde das crianças, e o direito de serem atendidas por profissionais qualificados são abordadas no documento Parâmetros e Indicadores de Qualidade para as Escolas Municipais que ofertam Educação Infantil, mas ainda não são uma realidade em todas as unidades. Problemas como estrutura física que possibilite ações e aprendizagem às crianças, falta de profisssionais, diretores de unidades sem perfil de liderança adequado, desgaste emocional da equipe de funcionários, entre outros, ainda são pontos a ser melhorados para atingir um nível de excelência na qualidade do atendimento.

\section{A evolução do número de matrículas e construção de unidades de atendimento em Curitiba}

Dados da Prefeitura Municipal de Curitiba, por meio da Secretaria Municipal de Educação, mostram um avanço no atendimento da educação infantil. Em 2010, o número de crianças atendidas teve crescimento de $65 \%$ em relação a 2001.

Para acompanhar esse avanço durante os últimos dez anos, a prefeitura da cidade investiu na ampliação dos Centros Municipais de Educação Infantil (CMEIs) existentes e na construção de novos equipamentos para atender à demanda de vagas (ver Tabela 2).

TABELA 2 - Evolução do número de matrículas em educação infantil em Curitiba e construção de novos Centros Municipais de Educação Infantil

\begin{tabular}{c|c|c|c|c|c|c|c|c|c|c|c}
\hline & 2001 & 2002 & 2003 & 2004 & 2005 & 2006 & 2007 & 2008 & 2009 & 2010 & 2011 \\
\hline $\begin{array}{c}\text { Matrículas } \\
\text { na } \\
\begin{array}{c}\text { educação } \\
\text { infantil }\end{array}\end{array}$ & 15.024 & 14.267 & 16.745 & 19.000 & 19.513 & 20.491 & 21.534 & 23.910 & 24.534 & 24.890 & 30.902 \\
\hline CMEIS & 124 & 124 & 139 & 146 & 152 & 155 & 157 & 163 & 170 & 171 & 180 \\
\hline
\end{tabular}

Fonte: IPPUC e INEP - Quadro Censo Escolar 2001 a 2011. 
Os investimentos na construção de mais equipamentos de atendimento são constantemente divulgados pela prefeitura de Curitiba. Para 2012, a prefeitura informou o investimento de 24,7 milhões de reais em obras para a ampliação da estrutura, com a construção de mais 18 novas unidades e 3,6 mil novas vagas na educação infantil.

Curitiba, segundo o Censo 2010 do Instituto Brasileiro de Geografia e Estatística (IBGE), tem o maior percentual de crianças de 0 a 3 anos frequentando creches, entre as capitais com mais de 1 milhão de habitantes: 39,5\%. A meta nacional prevista no PNE é atingir 50\% de atendimento na educação infantil até 2020.

\section{Vagas necessárias}

O número de vagas necessárias para atender à demanda da população é incerto. Em 2002, o Ministério Público do Paraná (MP-PR) recebeu um procedimento investigatório solicitado pela $1^{\text {a }}$ Vara da Infância e Juventude de Curitiba reivindicando a apuração da quantidade de vagas. No ano de 2004, o Ministério Público realizou um levantamento, juntamente com os Conselhos Tutelares, revelando a existência de 45 mil crianças que não tinham conseguido uma vaga em alguma creche em Curitiba. $\mathrm{Na}$ época, a prefeitura de Curitiba contestou os números apresentados, justificando que o levantamento foi realizado a partir de um cadastro de fila de espera em que os nomes das crianças estavam duplicados, por vezes até triplicados, pois os pais procuram mais de uma unidade, na tentativa de conseguir uma vaga, efetivando, dessa forma, novos cadastros de espera, portanto o déficit real não chegaria a 10 mil crianças.

Após esse episódio, a prefeitura de Curitiba atualizou o cadastro da fila de espera e investiu em um novo sistema de cadastro informatizado que pudesse apurar a real demanda.

Depois de vários anos sem saber o número de vagas necessárias para atender à demanda da população, em 2008 a prefeitura de Curitiba concluiu que havia a necessidade de abrir 12.380 novas vagas para zerar a fila de espera na educação infantil. Portanto, estimando que em 2008 o número de matrículas na educação infantil foi de 23.910 crianças, e a demanda apontada pela Prefeitura de Curitiba era de 12.380 crianças, seria necessário um aumento em torno de $50 \%$ na estrutura física, além de um investimento em mão de obra profissional qualificada para atender a essa necessidade.

\section{A taxa de natalidade em Curitiba}

Apesar de todo o investimento em educação para ampliação da oferta de atendimento a crianças de 0 a 5 anos, outro dado importante a ser observado é a diminuição da taxa de natalidade na população de Curitiba, conforme dados apontados pela Secretaria Municipal de Saúde (Figura 1). 


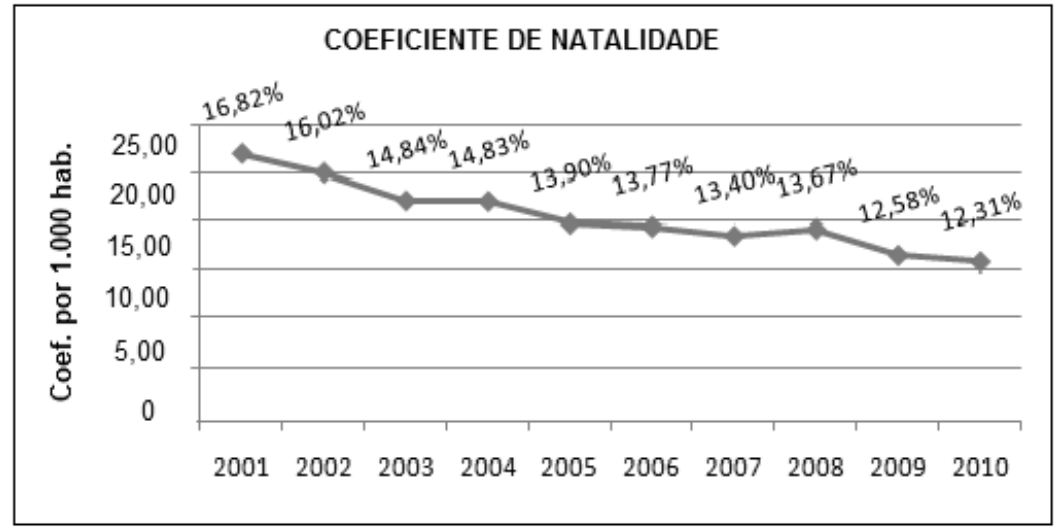

FIGURA 1 - Coeficiente de Natalidade: 2001 a 2010.

Fonte: SMS/CE-SINASC.

É importante afirmar que, embora a taxa de natalidade de Curitiba tenha diminuído, o mesmo não aconteceu com o número de habitantes na cidade (ver Tabela 3).

Tabela 3 - Evolução do número de habitantes e nascidos vivos em Curitiba

\begin{tabular}{c|c|c|c|c|c|c|c|c|c}
\hline & $\mathbf{2 0 0 1}$ & $\mathbf{2 0 0 2}$ & $\mathbf{2 0 0 3}$ & $\mathbf{2 0 0 4}$ & $\mathbf{2 0 0 5}$ & $\mathbf{2 0 0 6}$ & $\mathbf{2 0 0 7}$ & $\mathbf{2 0 0 8}$ & $\mathbf{2 0 0 9}$ \\
\hline $\begin{array}{c}\text { Popula } \\
\text { ção }\end{array}$ & $\begin{array}{c}1.610 . \\
221\end{array}$ & $\begin{array}{c}1.644 . \\
599\end{array}$ & $\begin{array}{c}1.671 . \\
193\end{array}$ & $\begin{array}{c}1.697 . \\
703\end{array}$ & $\begin{array}{c}1.757 . \\
903\end{array}$ & $\begin{array}{c}1.788 . \\
560\end{array}$ & $\begin{array}{c}1.818 . \\
948\end{array}$ & $\begin{array}{c}1.851 . \\
213\end{array}$ & $\begin{array}{c}1.872 . \\
122\end{array}$ \\
\hline $\begin{array}{c}\text { Nascid } \\
\text { os } \\
\text { vivos }\end{array}$ & 27.090 & 26.344 & 24.807 & 25.171 & 24.442 & 24.625 & 24.375 & 25.315 & 23.545 \\
\hline
\end{tabular}

Fonte: Adaptado do quadro: Nascidos Vivos em Curitiba - 1995 a 2009. SMS/CE-SINASC

Vários fatores contribuem para a diminuição da taxa de natalidade, como os programas de planejamento familiar, que oferecem métodos contraceptivos. Tem-se observado que a população de Curitiba está ficando "mais velha", situação comparável ao processo histórico de envelhecimento das cidades europeias.

Se a estrutura para atendimento às crianças está sendo ampliada, e em contrapartida o número de crianças nascidas na cidade diminui, é fato que essa estrutura, em um determinado momento, será suficiente para atender a todas as crianças na fase da educação infantil, e então, se a taxa de natalidade continuar em declínio, os recursos destinados à educação poderão ser empregados na qualidade e manutenção dos espaços existentes. 


\section{Novos desafios e possibilidades}

Planejar a construção de novos espaços na educação infantil com base na demanda de vagas reprimidas e que ainda não foram contempladas pode caracterizar um erro de gestão quando há promessas eleitoreiras e assistencialistas para zerar a fila de espera para a educação infantil. A estrutura física desses espaços é preparada exclusivamente para o atendimento de crianças, em salas com mobiliário apropriado, banheiros com sanitários adequados, entre outros investimentos, que poderão não ter utilidade se houver um grande número de Centros de Educação Infantil sem crianças para atender. É importante mencionar também o investimento em recursos humanos, pois os profissionais da administração pública são contratados por meio de concursos públicos e têm estabilidade garantida.

Pensando em novos desafios, o gestor poderá investir em novos espaços para atender à atual demanda, de forma que a estrutura também possa ser utilizada em outros serviços para garantir o bem-estar da população, otimizando, dessa forma, as verbas públicas.

Uma alternativa possível é investir em espaços para atender a uma futura demanda de serviços públicos voltados para uma parcela da população que está em constante crescimento e que clama por novas políticas públicas: os idosos.

As políticas públicas voltadas ao atendimento do idoso ainda são recentes na história do Brasil, e justifica-se suas recentes ações implementadas nos últimos anos com o avanço da evolução demográfica do país, conforme apontada pelos índices do Instituto Brasileiro de Geografia e Estatística (IBGE). Esse "envelhecimento" da população é um reflexo do aumento da expectativa de vida, causado pelos avanços realizados na área da saúde e pela redução das taxas de natalidade, que tem como consequência o aumento da população com mais de 60 anos, que em uma década cresceu 17\% (IBGE, 2000), em relação ao número total de habitantes no país, além do aumento da expectativa de vida, que em 2010 era de 73,48 anos e evolui a cada ano.

Segundo dados da Organização Mundial de Saúde (OMS), até 2025 o Brasil será o sexto país do mundo com o maior número de pessoas idosas. Desta forma, fica clara a necessidade de serem criadas políticas sociais que preparem a sociedade para essa realidade.

Frey (2000) relata a importância de políticas setoriais que estão englobadas nas políticas públicas e são mais focadas em uma área específica, como políticas de saúde, de meio ambiente, de educação e, neste caso, para o idoso. As políticas setoriais se caracterizam por sua maior dependência em relação às dimensões da política, ou seja, as mudanças nas instituições políticas (polity), nos processos políticos (politics) e nos conteúdos da política (policy) que afetam mais as políticas setoriais do que as públicas. Promover políticas setoriais voltadas aos interesses do idoso é um desafio, pois ainda é grande a desinformação sobre as necessidades do idoso e sobre as particularidades do envelhecimento em nosso contexto social.

O envelhecimento humano é uma ciência ainda pouco estudada, um bom exemplo disso é, em um passado pouco distante, a necessidade de os médicos brasileiros que desejassem se especializar em geriatria terem que ir estudar na Europa. Há poucos exemplos de sucesso de políticas públicas para o setor, como a recente implantação de um hospital exclusivo para atendimento a idosos em Curitiba e a criação, em Brasília, da primeira Subsecretaria para Assuntos do Idoso, que instituiu o Estatuto do Idoso, regido por princípios que registram o direito das pessoas mais velhas a uma ocupação e trabalho, acesso à cultura, à justiça, à saúde e à sexualidade, além, é claro, de poder participar da família e da comunidade. Promover esse tipo de qualidade de vida ao idoso é dever da sociedade atual, pois atualmente 
se define qualidade de vida como estar bem socialmente, ter boas condições financeiras, saúde, moradia, lazer e educação.

Ainda há muito que se fazer. Com o planejamento público voltado a ações para essa população, percebe-se ainda que a seletividade na Lei Orçamentária Anual (LOA) exclui muitos idosos por estarem fora de políticas que beneficiem projetos como os vinculados à pobreza. Embora novas políticas públicas sejam necessárias em todos os setores, com o "envelhecimento" da população, essas políticas devem ser planejadas com o envolvimento de toda a sociedade.

Heidemann e Salm (2009) apontam que a implementação de políticas eficazes voltadas para o senso de bem comum só atinge seus objetivos com a participação de outros agentes da sociedade (associações, indústrias, ONGs, etc.) na sua elaboração, implementação e avaliação. A elaboração e implementação devem ainda ser no modelo sistêmico de gestão pública. A teoria sistêmica pode ser definida como um conjunto identificável de instituições e atividades da sociedade que funcionam no sentido de transformar demandas em decisões oficiais, com o apoio indispensável de toda a sociedade, que influencia as políticas desenvolvidas. Esse apoio só é possível quando a sociedade aceita os resultados das eleições, cumprindo as leis, pagando impostos, colaborando e aceitando as decisões políticas.

Portanto, planejar o atendimento da educação infantil com espaços que poderão estar adaptados para atender à nova realidade da população pode ser classificado dentro dos princípios básicos da boa governança: ser eficiente e eficaz.

\section{Considerações finais}

Historicamente, a oferta do atendimento na educação infantil surgiu com a transformação da sociedade econômica e com a Revolução Industrial, que criou a necessidade de as mães saírem em busca de uma oportunidade de emprego e ter que deixar os filhos em um lugar que pudesse substituir o papel da família na educação das crianças. Desta forma, o setor púbico, comprometido com o desenvolvimento econômico, se organizou para criar espaços com caráter assistencialista, nos quais as crianças pudessem ser deixadas e cuidadas durante o período em que as mães estivessem trabalhando, mas não houve preocupação com a questão da qualidade da educação dessas crianças. Tratar as crianças da educação infantil como parte de um processo educacional é algo recente na história do Brasil.

Mesmo com todo o investimento feito até hoje, a demanda ainda é insuficiente. Embora com os direitos garantidos por Lei, muitas famílias não conseguem para os filhos uma vaga em instituições públicas que ofereçam educação infantil.

Em contrapartida, as mudanças culturais da sociedade estimulam que os rumos das ações do serviço público sejam sempre revistos, levando em consideração índices como a diminuição taxa de natalidade e o aumento do número de idosos. A observação desses indicadores deve orientar o processo de implantação de políticas públicas no setor da educação, e todo esse investimento na estrutura física poderá ser utilizado para o desenvolvimento educacional das crianças de forma eficiente, com uma estrutura preparada para atender outros setores da sociedade, como determinadas necessidades dos idosos.

Considerando que atualmente a estrutura do ambiente educacional atende a uma demanda de acordo com suas capacidades físicas, e que em alguns casos esse atendimento está comprometido por atuar no limite extremo de sua capacidade, essa mesma estrutura 
poderá ser utilizada para garantir que as atividades previstas nos instrumentos que buscam a qualidade na educação sejam plenamente atingidas.

Com demanda e estrutura física adequadas, número suficiente de profissionais qualificados e recursos garantidos para a educação básica, este poderá ser o momento da tão esperada revolução na educação.

\section{REFERÊNCIAS}

BRASIL. Ministério da Educação. Lei n. 9.394, de 20 de dezembro de 1996. Estabelece as Diretrizes e Bases da Educação Nacional. Diário Oficial da República Federativa do Brasil, Brasília, DF, 23 dez.1996.

Disponível

Ministério da Educação. Plano Nacional de Educação - PNE. Brasília: INEP, 2001.

<http://www.inep.gov.br/download/cibec/2001/titulos_avulsos/miolo_PNE.pdf $>$. Acesso em 25 jul. 2013.

. Ministério da Educação. Parâmetros Básicos de Infraestrutura para Instituições de Educação Infantil, 2006.

Constituição (1988). Constituição da República Federativa do Brasil: Texto constitucional promulgado em 5 de outubro de 1988, com as alterações adotadas pelas Emendas Constitucionais n. ${ }^{\text {os }} 1 / 92$ a 56/2007 e pelas Emendas Constitucionais de Revisão n. ${ }^{\text {os }}$ 1 a 6/94. Brasília, DF: Senado Federal, 2008.

CURITIBA. Secretaria Municipal da Educação. Parâmetros Municipais de Qualidade para as Escolas que ofertam a educação infantil, 2009.

FREY, Klaus. Políticas públicas: um debate conceitual e reflexões referentes à prática da análise de políticas públicas no Brasil. Planejamento e Políticas Públicas, v. 2, n. 21, p. 211 259, jun. 2000.

HEIDEMANN, Francisco G.; SAlM, José Francisco (Org.). Políticas Públicas e desenvolvimento: bases epistemológicas e modelos de análise. Brasília: Editora da UnB, 2009 .

IBGE. Censo 2000. Disponível em:

<http://www.ibge.gov.br/home/estatistica/populacao/default_censo_2000.shtm>. Acesso em: 25 jul. 2013.

IBGE. Pesquisa Nacional por Amostra de Domicílio (PNAD). 2008. Disponível em: <http://www.ibge.gov.br/home/estatistica/populacao/trabalhoerendimento/pnad2008/>. Acesso em: 25 jul. 2013.

PARANÁ. Conselho Estadual de Educação. Deliberação no 02/2005 - CEE-PR Normas e Princípios para a Educação Infantil no Sistema de Ensino do Paraná, 2005.

UNESCO. Relatório de Monitoramento Global de EPT 2010: Alcançar os marginalizados, 2010. Disponível em: 〈http://unesdoc.unesco.org/images/0018/001865/186525por.pdf>. Acesso em: 25 out. 2012. 